\title{
UN MANUSCRITO Y DOS CONVENTOS (SIGLOS XIV-XVI). LA REGLA EN CATALÁN DE SANTA CLARA DE VILAFRANCA DEL PENEDÈS Y SANTA MARÍA DE JERUSALÉN*
}

\author{
POR \\ BLANCA GARI ${ }^{1}$ \\ Universitat de Barcelona \\ Y \\ NÚRIA JORNET-BENITO² \\ Universitat de Barcelona
}

\section{RESUMEN}

Este trabajo parte de un estado de la cuestión de lo que hoy sabemos sobre dos conventos de clarisas catalanas entre los siglos XIV al XVI y analiza un manuscrito que recoge la Regla de Urbano IV traducida al catalán con toda probabilidad para las clarisas del primer monasterio, Santa Clara de Vilafranca del Penedès, que en el siglo XVI acabará uniéndose al segundo de ellos, Santa María de Jerusalén. El estudio del manuscrito y sus poseedoras se encuadra en el marco más general de una investigación que busca contextualizar los objetos en relación; sea con su «materialidad» a través de las huellas, textuales o no, que han ido dejando en él los procesos de producción, manipulación y uso; sea con su «espacialidad» a través de la red de significaciones que crean sus contextos de uso, custodia y relación performativa.

PALABRAS CLAVE: espiritualidad; clarisas; libros; regla; Baja Edad Media.

\section{A MANUSCRIPT AND TWO CONVENTS (14TH-16TH CENTURIES). THE RULE IN CATALAN OF SANTA CLARA DE VILAFRANCA DEL PENEDÈS Y SANTA MARÍA DE JERUSALÉN}

\begin{abstract}
This work starts with a state of the question of what we know today about two convents of Catalan Poor Clares between the 14th and 16th centuries and analyses a manuscript that contains the Rule of Urban IV translated into Catalan in all probability for the Poor Clares of the first monastery, Saint Clare of Vilafranca del Penedès, which in the 16th century would end up joining the second of them, Saint Mary of Jerusalem. The study of the manuscript and its owners falls within the more general framework of an investigation that seeks to contextualize the objects in relation; either with their «materiality» through the traces, textual or not, that the processes of production, manipulation and use have left in it; or with their "spatiality" through the network of meanings that create their contexts of use, custody and performative relationship.
\end{abstract}

KEY WORDS: spirituality; Poor Clares; books; rule; Lower Middle Ages.

CÓMO CITAR ESTE ARTícUlo / CITATION: Garí, Blanca y Núria Jornet-Benito. 2020. «Un manuscrito y dos conventos (siglos XIVXVI). La regla en catalán de Santa Clara de Vilafranca del Penedès y Santa María de Jerusalén». Hispania Sacra LXXII, 145: $39-49$. https://doi.org/10.3989/hs.2020.003

Recibido/Received 28-06-2017

Aceptado/Accepted $\quad$ 03-02-2018

\footnotetext{
* Esta investigación se gestó en el proyecto de MINECO (HAR2014 52198-P) Paisajes Espirituales y ha culminado en el proyecto del Ministerio de Ciencia, Innovación y Universidades (PG2018-095350-B-100) Monastic Landscapes.

1 gari@ub.edu / ORCID iD: https://orcid.org/0000-0001-9269-1774

2 jornet@ub.edu / ORCID iD: https://orcid.org/0000-0002-3942-4682
} 


\section{INTRODUCCIÓN}

Este trabajo parte de un estado de la cuestión de lo que hoy sabemos sobre dos conventos de clarisas catalanas entre los siglos XIV al XVI y analiza su relación con un manuscrito que recoge la Regla de Urbano IV, traducida al catalán con toda probabilidad para las clarisas del primer monasterio, Santa Clara de Vilafranca del Penedès, que en el siglo XVI acabará uniéndose al segundo de ellos, Santa María de Jerusalén. Que las comunidades de Clarisas catalanas tuvieron una relación rica y fluida con los libros empieza a ser algo que no hace falta demostrar. ${ }^{3}$ En todos aquellos casos en los que la documentación nos permite abrir las puertas de la fábrica monástica y penetrar siquiera parcialmente en su interior, aparecen ante nuestros ojos múltiples ejemplos. A decir verdad, libros han sobrevivido bien pocos, pero los archivos monásticos hablan en cambio, y reiteradamente, de su existencia. Conocemos bastante bien el caso de Sant Antoni y Santa Clara de Barcelona, la primera fundación clarisa en tierras catalanas; ${ }^{4}$ allí veinte inventarios de sacristía seriados a lo largo de tres siglos y diez inventarios de convento, además de albaranes y otra documentación similar, nos hablan de la riqueza y variedad de la «biblioteca» monástica así como de su dispersión por los espacios de uso que con frecuencia, al menos en el siglo XIV, son también los espacios de custodia. ${ }^{5}$ Santa María de Pedralbes, la fundación de la reina Elisenda de Montcada, es otro buen ejemplo; ${ }^{6}$ en este monasterio de clarisas de nuevo los inventarios de convento son los que hablan de la existencia y del uso performativo de numerosos manuscritos, pero también diversos registros documentales mencionan sea la compra de libros, sea la compra de materiales para restaurarlos, o pagos para la reparación de los mismos. ${ }^{7}$ De ambos monasterios mencionados se conservan además un cierto número, aunque reducido, de manuscritos medievales que han llegado hasta nuestros días. ${ }^{8}$ No es este el caso de Santa Clara de Manresa, el tercer monasterio de clarisas catalanas que ha sido estudiado hasta hoy en profundidad, pues de él no se ha conservado ningún libro, pero sí poseemos en cambio múltiples noticias sobre la presencia de un número importante de volúmenes en el monasterio, número que crece y se enriquece a lo largo de los siglos XIV y XV; ${ }^{9}$ las informaciones nos llegan en este caso a través de protocolos notariales que muestran la relación fluida entre la comunidad y los habitantes, hombres y mujeres, de la ciudad de Manresa; los libros salen y sobre todo entran en forma de donaciones al monasterio; a veces se trata de importante manuscritos, a veces estos son solemnemente aceptados en actos que recogen los nombres de las monjas de la comunidad,

\footnotetext{
3 Garí y Jornet-Benito 2017, Garí 2017.

4 Jornet-Benito 2007, 2015. Más en general, para las clarisas en los reinos peninsulares véase Omaechevarría 1972 y Castro y Castro 1989.

5 Garí y Jornet-Benito 2017, 489.

6 Castellano i Tresserra 1998.

7 Sanjust Latorre 2010.

8 Para Sant Antoni y Santa Clara de Barcelona véase especialmente Garí y Jornet-Benito 2017. En la actualidad se está trabajando en el marco del Proyecto Paisajes Espirituales en la elaboración de una base de datos de los inventarios del monasterio y una infografía que los visualice, http://www.ub.edu/proyectopaisajes/index.php/es/ejes/ monasterio-interior?id=98 Para el caso de Pedralbes ver Castellano Tresserra 1998, 331; 2014.

9 Rosillo-Luque 2013.
}

la descripción del códice, el lugar donde estará situado y la función performativa y devocional del mismo; la visión de conjunto es que la comunidad de Manresa tuvo una notable relación con la cultura escrita. ${ }^{10}$ Ciertamente, no podemos decir lo mismo de los restantes catorce monasterios de clarisas catalanas, no necesariamente porque su situación haya sido diferente, sino porque sus fondos o han desaparecido en diversos episodios históricos, o se conservan solo parcialmente y dispersos; la tarea de recopilarlos, en este último caso, resta aún pendiente. ${ }^{11}$ Pero aun así, nos son conocidos algunos volúmenes manuscritos que proceden de algunos de estos conventos. La Regla en catalán conservada hoy en la Biblioteca Nacional de Catalunya es uno de ellos y se asocia como mínimo a dos conventos: Santa Clara de Vilafranca del Penedès y Santa María de Jerusalén de Barcelona. Analizar lo que hoy sabemos de ambos conventos y contextualizar en ellos la regla es pues el objetivo principal de este estudio.

Una regla no es para una comunidad un manuscrito cualquiera. Ocupa un lugar central en la vida diaria del convento y en las prácticas que regulan las relaciones comunitarias, las devociones, la memoria e identidad de la comunidad y los ritos de paso en el interior de la misma. La Regla es un libro destinado a ser leído y escuchado en diferentes espacios y momentos del día, pero también tocado y pasado de una mano a otra en ciertos rituales como podría ser la toma del velo por parte de las novicias. ${ }^{12}$ Los inventarios de Sant Antoni i Santa Clara de Barcelona nos hablan de la existencia de más de una regla en el convento. ${ }^{13}$ Los inventarios de Pedralbes, donde el manuscrito de la regla se ha conservado, como luego veremos, también nos hablan de ella. Para el volumen que nos proponemos estudiar aquí no tenemos en cambio noticias paralelas que lo mencionen. Pero conocemos la historia de los dos monasterios que con toda probabilidad lo poseyeron sucesivamente y podemos imaginar con alto grado de certeza el paso de este volumen de una comunidad a otra, viajando de la mano de las últimas monjas de Santa Clara de Vilafranca hasta su ingreso en Santa María de Jerusalén. ¿Qué sabemos de ambos monasterios? Una monografía exhaustiva sobre ellos resta aún pendiente, pero partiendo de los estudios dispersos existentes, de algunos datos de archivo nuevos y de una comparativa con los trabajos más generales sobre el monacato femenino occidental, podemos dibujar un panorama de sus orígenes, proceso fundacional y características bastante concreto. En todo caso, se trata de dos monasterios de orígenes y características totalmente diversas: una fundación real el primero y una comunidad de terciarias el segundo, fruto del deseo de dos mujeres viajeras y peregrinas ¿Qué vínculos los unieron? ¿qué circunstancias hicieron confluir ambas comunidades?

10 Torres Cortina 2004 y Rosillo Luque 2016.

11 Costa Badia, Sancho i Planas y Soler Sala 2017.

12 Garí y Jornet-Benito 2017, 506-507.

13 En los inventarios 1419 y 1421 aparecen dos reglas entre los libros del refectorio: Arxiu Monestir de Sant Benet de Montserrat, Monestir de Santa Clara de Barcelona (AMSBM, MSCB), vol. 31, núm. 5, f. 7. y $A M S B M / M S C B$, vol. 31, núm. 6; mientras que en los restantes una única se encuentra en la iglesia, probablemente en el coro. Siglas empleadas $\mathrm{AMSBM}=$ Sant Benet de Montserrat, $\mathrm{MSCB}=$ Monestir de Santa Clara de Barcelona, AHRMSMP = Arxiu Històric del Reial Monestir de Santa Maria de Pedralbes. 


\section{LAS DOS COMUNIDADES MONÁSTICAS}

La fundación del monasterio de Santa Clara de Vilafranca del Penedès fue obra de Blanca de Nápoles, esposa del rey Jaume II. Aunque se han conservado pocas informaciones sobre los orígenes de esta comunidad, sabemos por la documentación de otro monasterio de clarisas catalanas, Sant Antoni i Santa Clara de Barcelona, que en 1300 el cardenal protector de la Orden encargó al ministro provincial de Aragón, al guardián del convento de Barcelona y al de Vilafranca del Penedès, que llevaran adelante la construcción de una comunidad de clarisas en esta villa; en el documento se alude al interés del propio rey Jaume II, y se manda que tres o cuatro monjas de la comunidad de Barcelona sean transferidas al nuevo monasterio. ${ }^{14}$ La propia Blanca de Anjou al hacer testamento en 1308 destina al monasterio de clarisas de Vilafranca que se ha construido recientemente, «noviter constructi», la importante suma de 100 libras destinadas a la construcción de la iglesia «pro opere et fabrica ecclesie eorundem», construcción que debía estar, por tanto, aun en sus comienzos..$^{15}$ En los años sucesivos la Corona seguiría favoreciendo el monasterio al que Jaume II coloca bajo su especial protección en $1310 .{ }^{16}$ Que la reina personalmente fue su principal promotora y fundadora nos lo confirma años más tarde en 1325, ya muerta la reina, un documento del infante Alfonso, futuro rey e hijo de Blanca y Jaume II, en el que declara que quiere seguir la devoción de su madre, la cual había fundado e instituido el monasterio de menoretes de Vilafranca "fundavit et instituit monasterium Minorissarum Villafranchae», y en su memoria asigna al convento una renta perpetua de 100 "starellos» (esterells) de trigo anuales. ${ }^{17}$ Otros privilegios se suceden posteriormente como la concesión de Alfonso el Liberal en 1384 a la abadesa de entrar el vino sin pagar derechos por ello y la exención del pago de talles, host y cavalcada al procurador, así como la prohibición de establecer burdeles o ejercer la prostitución en la calle de las Menoretes. ${ }^{18}$

A pesar de no conocer la ubicación exacta de la fábrica monástica en la ciudad de Vilafranca, debido a su temprana desaparición en $1569,{ }^{19}$ el estudio combinado de la topografía urbana y las menciones documentales han permitido al historiador Josep Bosch, tal como recogen X. Costa, M. Sancho y M. Soler en su trabajo sobre la ubicación de los

14 AMSCB, MSCB, Col·lecció de pergamins, núm. 722. Es esta quizá la primera noticia concreta y cierta sobre la fecha de la fundación de la comunidad de Vilafranca que precede a las que se habían dado hasta el momento. Véase: Jornet-Benito 2007, 171.

15 Coy Cotonat 1909.

16 «recipimus sub nostra protectione, custodia et guidatico spetiali, monasterium sanctae Clarae situm iuxta Villam-francham » (Coy 1909, Reg. 204, f. 26)

17 «recelantes quod illustrissima domina Blancha, bone memoriae Regina Aragonum, mater nostra, fundavit et instituit monasterium minorissarum Villefranchae devotionem dicte domine matermatris nostre sequi volentes ad honorem Dei et gloriose Virginis Mariae et beate Clarae pietatis intuiti ac in remdeium anime eiusdem domine Regine felicis recordationis matris nostre, damus abbatisse et conventui ipsius monasterii perpetuo centum starellos frumenti annis singulis imperpetuum, percipiendos super aliqua villa seu villis nostris Insule Sardiniae» (Coy 1909, Reg. 894 f. 56) ACA.

18 Privilegio que fue confirmado por el rey Joan, en 1387 (Coy $1909,518)$ ACA, Registro de privilegios.

19 Sanahuja 1959, 811. monasterios de clarisas catalanas, hacer una propuesta sobre su posible emplazamiento. ${ }^{20}$ La comunidad de clarisas de Vilafranca, según argumentan, estaba ubicaba extramuros, en un espacio de expansión económica y agrícola de la ciudad: cerca del portal medieval de Santa Clara, en el lugar de confluencia entre la actual plaza Milà i Fontanals y la calle de Pines, donde antiguamente se situaba la Era del Sant Esperit, llamada así por encontrarse muy cerca del antiguo hospital del Sant Esperit (hoy iglesia de la Trinidad). ${ }^{21}$ De acuerdo con esta topografía, es posible que, al impulso real e institucional para la fundación monástica, se añadiera la existencia de una previa comunidad de mujeres con el perfil de beguinas que se situarían en el entorno del hospital para pobres y enfermos, fundado en 1272 por Bernat Llobet, pero nada seguro podemos decir al respecto. ${ }^{22}$ En todo caso, el impacto del monasterio sobre la toponimia urbana ha quedado fosilizado en la denominación de la actual calle de Santa Clara, que constituyó una de las principales vías de acceso al monasterio medieval.

Dentro del paisaje monástico ligado a la orden de Santa Clara en tierras catalanas, la fundación de Santa Clara de Vilafranca pertenece, por sus orígenes, a lo que podríamos definir como la segunda etapa de expansión de las clarisas en Cataluña y sigue un modelo fundacional, propio de este momento, en el que el papel de la Corona se acentúa y los conventos de clarisas nacen con frecuencia junto a un previo convento franciscano. ${ }^{23} \mathrm{Tal}$ es el caso de los franciscanos de Vilafranca, donde las primeras menciones a la presencia de frailes son de la década de 1240 , aunque la fundación del convento propiamente se realiza hacia 1283 , durando las obras hasta principios del siglo XIV. ${ }^{24}$ Asimismo el establecimiento de la casa de clarisas en la ciudad del Penedès entra dentro de los esquemas fundacionales o de expansión clarisa guiados por la acción de un núcleo madre, en este caso el de San Antoni i Santa Clara de Barcelona, y por el establecimiento de relaciones de fundación y filiación que acaba por poner en pie en Cataluña y fuera de ella un entramado de fundaciones en red. ${ }^{25}$ Pero quizá el aspecto más destacado en relación a los orígenes y de los primeros años de esta comunidad es ese firme apoyo de la reina y de su esposo. Sabemos que Blanca de Nápoles y Jaume II el Just fueron monarcas muy próximos a la causa franciscana en un momento delicado de la misma y que su particular cercanía a la figura e ideas de Arnau de Vilanova estuvo seguramente presente en su relación con la promoción monástica. En este sentido, y aunque es un tema en proceso de estudio, cabría destacar aquí la relación entre el convento y la comunidad de beguinos y beguinas espirituales presente en la ciudad de Villafranca así como de los círculos cercanos a Arnau de

20 Garí et al. 2014, 43-44 y nota 49; Costa, Sancho y Soler 2017.

21 Español 2008.

22 Jornet-Benito, N. "Santa Clara de Vilafranca» en CLAUSTRA. Atlas de espiritualidad femenina en los Reinos Peninsulares. Institut de Recerca en Cultures Medievals IRCVM, Universitat de Barcelona. URL: http://www.ub.edu/claustra [Consulta: 15-05-2017.

${ }_{23}$ Para esta periodización y el establecimiento de una topografía clarisa para las fundaciones catalanas, véase Webste 2000 y JornetBenito 2015.

24 Boadas Llavat 2014, 518.

25 Graña Cid 2017. 
Vilanova ${ }^{26}$ especialmente a partir del proceso inquisitorial que se desarrolló entre 1345 y $1346 .{ }^{27}$

De nuevo, es poca y sobretodo dispersa la documentación que se conserva o se conoce de esta comunidad que permita trazar la evolución que siguió. Según Pedro Sanahuja se trataría de una comunidad no muy grande que contaba en el año 1324 con 22 miembros; ${ }^{28}$ mientras que en 1386, son 17 las monjas las que junto a la abadesa Clara, nombran a Jaume Colteller como procurador para que actúe en su nombre y en el del convento en todos los asuntos relacionados con este y sus bienes..$^{29}$ En el año 1450 la comunidad tiene aún suficientes recursos para llevar a cabo la construcción de la sala capitular firmando un contrato con Ferrer Guerau, «mestre de cases» del Castell de la Granada. ${ }^{30} \mathrm{Sin}$ embargo Jill R. Webster da a conocer algunos datos de principios del siglo XV extraídos de la documentación de canciIlería, que muestran ya algunas de las problemáticas con las que se enfrentará la comunidad, y en general el resto de las comunidades clarisas, a lo largo de esta centuria: la vivencia de la regla en aspectos clave como la clausura, la disciplina, los límites del poder de la abadesa, o las dificultades que procedían de la presión del entorno. ${ }^{31}$

Entre 1494-1496, cuando el monasterio entró en el proceso de reforma en el marco de la observancia marcada por los Reyes católicos y el cardenal Cisneros, las visitas de los reformadores Daza y Fenals anotan que la comunidad se había reducido sensiblemente y contaba tan solo con siete monjas, dos legas y dos escolanas, bajo la dirección de la abadesa, y que sus rentas habían mermado de manera significativa. En su primera visita a esta comunidad el 19 de julio de 1494 insisten especialmente en la observancia de la clausura, de la vida en común, de la profesión de las "escolanas» y del vestido de las religiosas. Las frecuentes irregularidades en el cumplimento de las ordenaciones que establecieron los visitadores acabarían incluso con la deposición de la abadesa, Sor Brianda Soler, que fue encarcelada. ${ }^{32}$ El monasterio parece haber entrado a partir del 1500 en una crisis y un proceso de decadencia que seguiría afectando tanto al

26 Nieto-Isabel 2017, 429-448. Webster (2000, 300) concluye que una de las monjas de Santa Clara de Vilafranca, sor Agnès, era hermana de fra Pere Guerau, uno de los primeros terciarios de Cataluña.

27 Boadas $(2014,518)$ en su reciente aproximación a los franciscanos en Cataluña y en la cronología que aporta para la comunidad masculina de Vilafranca, concluye que en el proceso inquisitorial contra los beguinos o terciarios, los frailes y monjas también resultarían afectados. En el caso concreto de las clarisas, Perarnau $(2009,157)$ argumenta que quizás su implicación indirecta (defendiendo a ultranza que los restos mortales del beneficiado Ramon Punyera reposasen en su iglesia) se debiera probablemente más a razones personales que no necesariamente a una adhesión a las posiciones espirituales del difunto, acusado en el proceso.

28 Sanahuja 1959, 812.

29 Coll, Cazeneuve y Hernando1999, 354-356 doc. 177. La consulta y lectura de los protocolos notariales conservados en el Arxiu Comarcal de l'Alt Penedès, permitirán un mayor conocimiento de la comunidad en sus actividades económicas (censos, violarios...) y la relaciones con su entorno más inmediato (fieles, procuradores, notarios...).

30 Sanjust 2010, 378.

31 Webster 2000, 318. Concretamente nos da a conocer el caso de Sor Blanca Sa Fàbrega, que habría querido mantener un conjunto de privilegios como antigua abadesa y habría generado un importante litigio interno entre la comunidad en torno a los años 1405-1406.

32 Azcona 1957. Véase también acerca de la reforma García Oro 1969, 1971. número de hermanas, como directamente a las posibilidades de pervivencia de la propia comunidad, «muy rota en la disciplina, especialmente en la clausura», según Sanahuja. ${ }^{33}$ La extinción de esta comunidad finalmente se produjo entre 1567 y 1569 cuando, por disposición de Pío V, sus rentas se transferían al monasterio de Santa María de Jerusalén de Barcelona y la mermada comunidad (dos monjas junto a la abadesa) se trasladaba a Barcelona. ${ }^{34}$ Hasta 1835 este convento barcelonés cobraba aún censos del Penedès procedentes del monasterio de Santa Clara de Vilafranca, como nos recuerda Manuel Trenchs, que en 1926 había visitado la comunidad barcelonesa de Jerusalén, donde localizó algunos documentos del monasterio de Santa Clara, entre ellos dos interesantes inventarios de 1567 y 1571 que ofrecen una instantánea de esta comunidad en el momento de su extinción y traslado a Barcelona. ${ }^{35}$

Fue esta, Santa María de Jerusalén de Barcelona, la segunda comunidad poseedora del manuscrito catalán de la Regla que aquí analizamos. Para penetrar en el significado de este monasterio y explicar sus orígenes desde los que construirá su identidad comunitaria nos hemos de adentrar en la historia de las peregrinaciones de las «mulieres religiosae». Peregrinas y viajeras por devoción, muchas mujeres devotas, beguinas, o «mujeres de la penitencia» como les llaman con frecuencia las fuentes catalanas, emprendieron en la Edad Media el camino a diversos lugares sagrados, pero ante todo a Roma y Tierra Santa. Y es hacia allí hacia donde dirigió sus pasos Rafaela Pagesa en una fecha incierta de mediados del siglo XV. Como Sancha de Aragón en el siglo XIII, como Brígida de Suecia en el siglo XIV cuya compañera Sança se instaló tras su muerte en Barcelona, como Margery Kempe a principios del XV, y como tantas otras mujeres más cercanas y anónimas que quizá le sirvieron de modelo, ${ }^{36}$ esta terciaria franciscana de la población de Sarrià, cercana a Barcelona, quiso realizar por ella misma el largo viaje a Oriente, a los lugares santos en los que Cristo vivió y murió, para recorrerlos en una práctica performativa y devocional que otras, -y quizá ella misma más tarde-, realizaban virtualmente. Como ha mostrado Kathryn Rudy existen para el último periodo de la Edad Media múltiples ejemplos de manuscritos, obra de terciarias viajeras, que describen y reproducen su viaje a Roma y Jerusalén. Estos textos estaban destinados no solo a una lectura devota sino más bien a un uso performativo de los mismos en el interior de los claustros. Con ellos y a

\footnotetext{
33 Sanahuja 1959, 812.
}

34 Coy 1909, 519. Sin embargo, Trenchs (1926) precisa que de hecho todos los derechos, censos y censales pasaron, al extinguirse la comunidad, a los frailes claustrales de San Francisco de Vilafranca, y cuando estos fueron extinguidos y suprimidos por las bulas de Pío $\mathrm{V}$ (1574) entonces pasaron al monasterio de Jerusalén de Barcelona.

35 Trenchs1926, 240. Desgraciadamente, Trenchs solo publica, a falta de espacio en la revista, la parte del inventario relativa a la iglesia monástica.

36 Sobre el caso de Brígida y las mujeres que la rodeaban así como sobre sus conexiones con Barcelona está trabajando David CarrilloRangel. Un avance de sus resultados se encuentra en: Carrillo-Rangel, D. 2017. «Travelling Memories: Traces of Sor Sança, Companion of Birgitta of Sweden in Medieval Barcelona» Women's Literary Culture and the Medieval Canon. An International Network Funded by the Leverhulme Trust: https://blogs.surrey.ac.uk/medievalwomen/2017/05/26/travelling-memories-traces-of-sor-sanca-companion-of-birgitta-of-sweden-in-medieval-barcelona/ [Consulta: 26/06/2017]. 
través de ellos se llevaba a cabo la peregrinación virtual a los santos lugares y se replicaba la experiencia, no metafóricamente sino tan física y literalmente como fuera posible, implicando el cuerpo en la representación. ${ }^{37}$ Rafaela, en el camino de regreso a Cataluña visitó Roma, y después de trabar conocimiento en Italia con una viuda llamada Antonina de Pisa, viajo con ella a Barcelona con la decisión de fundar una comunidad de terciarias en la ciudad. E. Botines, J. Cabaleiro y MA. Duran piensan que no son otras sino Rafaela y Antonina las mujeres que aparecen mencionadas como "dones de la penitencia» en la carta dirigida por Alfonso el Magnánimo en 1453 a los Consellers de Barcelona apoyando su proyecto de abrir una casa en la ciudad en la que habitar y en la que acoger a otras mujeres viajeras y peregrinas. Sabemos que, por entonces, en 1453, ambas se encuentran en posesión de una bula de Nicolás $\mathrm{V}$ que les autoriza a la construcción de una casa para mujeres regida por una "maestra». ${ }^{38}$ De hecho, en 1456 Rafaela y Antonina presentan un suplicatorio al Consell de Cent para que se les conceda una ayuda para la construcción de un monasterio. Nace así la primera comunidad que había de ubicarse en el solar de unas casas anteriormente ocupadas por las dominicas Montsió y que ellas demolieron para la construcción de su monasterio de terciarias franciscanas. ${ }^{39}$ La casa fue puesta bajo la advocación de Santa María de Jerusalén, sin duda en memoria del viaje de Rafaela a Tierra Santa. Fue maestra de la comunidad la propia Rafaela y a su muerte lo fue sor Antonina de Pisa. La casa recibió el apoyo reiterado de la monarquía para llevar a buen término la construcción de la fábrica monástica, con la intervención explícita de la reina Joana Enríquez en la construcción de la iglesia y más tarde la de su hija Joana; la comunidad recibió también el apoyo del Consell de la Ciutat que facilitó la piedra. ${ }^{40}$

Todavía como comunidad de la orden tercera Santa María de Jerusalén entró en la dinámica de creación de redes fundacionales, promocionando en 1484 la emergencia de una nueva fundación denominada así mismo de Santa María de Jerusalén en la ciudad de Zaragoza. Santa María de Jerusalén de Barcelona pertenece por tanto a un modelo fundacional distinto al de la comunidad de Vilafranca, si bien característico de muchas órdenes femeninas, no solo clarisas, en el siglo XV. Un caso similar, sin ir más lejos, es el de las terciarias dominicas del Convent dels Àngels en la propia Barcelona, casa que se funda en 1461 y que se acoge a la segunda orden en $1497 .{ }^{41}$ Se trata pues de comunidades que viven un primera e importante etapa como terciarias respondiendo a un proyecto claro y explícito de sus fundadoras, y que solo más tarde acaban, por motivos complejos y diversos, por acogerse a la segunda orden, convirtiéndose en monasterios de clausura. Y así fue también para la comunidad de las peregrinas y viajeras. Después de 1494, ya

\section{Rudy 2011}

38 Paulí Meléndez 1970; Botinas, Cabaleiro y Duran 2002, 74-76.

39 Botinas, Cabaleiro y Duran 2002, 75.

40 Ibídem.

41 Paulí Meléndez 1941. Ahumada-Batlle L. de; Gras, M. «Mare de Déu dels Àngels i Peu de la Creu» Casanovas en CLAUSTRA. Atlas de espiritualidad femenina en los Reinos Peninsulares. Institut de Recerca en Cultures Medievals IRCVM, Universitat de Barcelona: http://www. ub.edu/claustra. [Consulta: 15/05/2017]. fallecida la fundadora, las sores de Santa María de Jerusalén deciden abandonar la orden tercera y adoptar la regla urbanista de la segunda orden de Santa Clara, trayendo a Barcelona para la nueva fundación monjas del monasterio de la Trinidad de Valencia, que llegaron a la ciudad el 24 de enero de aquel año. ${ }^{42}$ Dos años más tarde en 1496 adoptaban también la regla de la segunda orden las sores del convento filial de Zaragoza. ${ }^{43}$ A partir del siglo XVI Santa María de Jerusalén de Barcelona creció notablemente, alcanzado la comunidad una cifra de unas 70 monjas, y se mostró fuertemente activa. De esta comunidad salían en 1539 las fundadoras de Santa Lucia de Cagliari en Cerdeña. Y años más tarde las de Barcelona acogían a las últimas monjas de Santa Clara de Vilafranca del Penedès $-y$ recogían todo el patrimonio del convento menos afortunado-. Muy probablemente de manos de estas monjas penedesencas llega al monasterio a finales del siglo XVI el manuscrito de la Regla.

\section{EL MANUSCRITO}

El manuscrito, que contiene la regla de Urbano IV en catalán, se conserva actualmente en la Biblioteca de Catalunya. ${ }^{44}$ Se trata de un códice compuesto por:

- (ff. 1-1v.) la carta del cardenal de San Nicolás, Juan Gaetano Orsini, (autor del texto de la Regla) dirigida a las clarisas y en la que se habla de la propia traducción de la regla. La carta está escrita en catalán. «lohan per la misericòrdia divinal dia/cha cardenal de sent Nicholau en lo / carer Tullia. A les amades filles en Christ to / tes les abadesses e sors encloses de l'orde de / sancta Clara tramet salut en lo Senyor».

- (ff. 1v.-4) la bula, traducida al catalán, de aprobación de la Regla por Urbano IV del 18 de octubre de 1263. «Aquesta és la Regla per lo sanctíssim pare papa Urbà / quart dada e confermada a les sors de / sancta Clara en l'any mil e docents LXIII a / XV dies ans de les kalendes de noem-/-bre en lo temps de frare Bonaventura / ministre general de l'orde dels frares menors». Este texto se sitúa a manera de prólogo de la propia Regla.

- (ff. 4-30) la Regla: «In nomine Domini incipit regula sororum sancte Clare». Dividida en 26 capítulos. El texto está en catalán. Los títulos de los epígrafes en cambio en latín. Colofón: «Dada en la ciutat vella lo quinzen dia ans de les kalendes de noembre, l'any terç del nostre pontificat».

- (f. 31) una cronología de la orden de santa Clara. En latín.

El manuscrito presenta las rúbricas de los capítulos de la regla, en rojo; calderones en rojo e iniciales alternadas en este mismo color y en azul. En el primer folio (f.1 v.), se muestra una gran inicial historiada iluminada, con la imagen del Papa acompañado de dos cardenales y de santa Clara, que lleva un documento en la mano, junto a dos monjas. En el

42 Sales y Moles 1761. Paulí Meléndez 1970; Botinas, Cabaleiro y Duran 2002, 75.

43 Paulí Meléndez 1970.

44 Biblioteca de Catalunya, Ms. 3723. En la actualidad, Araceli Rosillo, archivera del Arxiu-Biblioteca dels Franciscans de Catalunya, está realizando la edición completa de este manuscrito, en el marco de un corpus más amplio de fuentes clarianas inéditas o no publicadas. 
margen inferior del folio $1 \mathrm{r}$ aparece una marca de propiedad en letra del siglo XVII, en la que se precisa que el códice pertenece al convento de Santa María de Jerusalén de Barcelona. ${ }^{45}$ Según consta en su catálogo, en abril de 1990 este manuscrito pasó a formar parte de la colección de la Biblioteca de Catalunya. Este catálogo sitúa la producción del manuscrito en la primera mitad del siglo XV (1401-1450); mientras que otros catálogos, que analizan las características del texto y su traducción, hablan de una fecha anterior: 1300-1400 (según BITECA) ${ }^{46}$ siglo XIV (según TRANSLAT). ${ }^{47}$ Este último censo de traducciones clasifica concretamente dos reglas de las clarisas en catalán: la que denominan Versión-1 conservada en Pedralbes y la Versión 2, que es la del manuscrito que nos ocupa. ${ }^{48}$ Desde un análisis estilístico, la historiadora del arte Francesca Español sitúa la miniatura dentro de los cánones representativos del estilo pictórico hispano-flamenco, asimilado en este caso por un artista autóctono, activo en Cataluña a mediados del siglo XV. ${ }^{49}$

Para analizar adecuadamente este manuscrito creemos necesario enmarcarlo en primer lugar en el conjunto de códices que recogen en los siglos XIV y XV la regla de las clarisas traducida al catalán; ${ }^{50}$ en segundo lugar, detenernos sobre los textos que acompañan la traducción de la regla en nuestro manuscrito (la carta del cardenal Orsini; la bula papal y la cronología franciscana); en tercer lugar, queremos prestar atención a las marcas de uso que muestra nuestro códice; y finalmente querríamos dar vida a este manuscrito reflexionando sobre los usos del mismo en el interior de las comunidades que lo poseyeron.

\subsection{La Regla las clarisas en catalán}

El manuscrito que contiene la Regla de Urbano IV en catalán más conocido hasta el momento es la llamada Versión-1, la de Pedralbes; cuyo texto ha sido ya objeto de transcripción y estudio histórico. ${ }^{51}$ Se trata de un códice producido y conservado en el monasterio de Santa Maria de Pedralbes, en Barcelona, que presenta diferencias significativas respecto al que nos ocupa. ${ }^{52}$ Para empezar, contenía, además de la traducción al catalán de la Regla, el texto en latín, tal como se describe en su encabezamiento: "Aquest libre és del convent de les dones sors menors de l'honrat monestir de senta Maria de Pedralba, e és así la regla lur escrita en latí e en romanç»; hecho que se menciona asimismo en el inventario de bienes de la comunidad que hizo la abadesa sor Sibilia de Caixans en 1364, donde se anota que en la sacristía de la comunidad se encuentra «la regla

45 «Del convent de les monges Hierusalem de Barcelona».

46 Bibliografia de textos antics catalans, valencians $i$ balears (BITECA): http://bancroft.berkeley.edu/philobiblon/biteca_ca.html [Consulta: 30/05/2017].

47 TRANSLAT-Base de dades de traduccions al català medieval: http://www.narpan.net/translat-db.html [Consulta: 30/05/2017].

48 TRANSLAT-Base de dades de traduccions al català medieval: http://www.narpan.net/translat-db.html [Consulta: 30/05/2017].

49 Español 2009, 292.

50 Sobre la relación de las comunidades femenines con los procesos directos o indirectos de redacción, modificación, traducción de la regla nos parece interesante tener en cuenta las reflexiones de Lehmijoki-Gardner 2004.

51 Saldes 1912a, 1912b, 1912c. González y Rubió 1982.

52 AHRMSMP, R-24. de les sors en latí e en romans en un volum»..$^{53} \mathrm{El}$ códice de Pedralbes recoge además: un texto que rememora la fundación del monasterio en 1327 por la reina Elisenda de Montcada; las ordenaciones del papa Benedicto XII en latín y su traducción catalana; la copia una carta del cardenal de San Nicolás, Juan, sobre los visitadores; y las ordenaciones en latín de fra Guillermo de Salanova, ministro provincial de Aragón.

Fra Ambròs de Saldes, ${ }^{54}$ en su estudio y transcripción de esta versión catalana de la Regla, que clasificaba como la más antigua conocida, datándola en la primera mitad del siglo XIV, anotaba también la existencia de otros dos códices, en su opinión más modernos, de la Regla en catalán que el mismo pudo consultar en el momento que escribía, en 1912-: uno, conservado entonces en el mismo monasterio de Pedralbes; ${ }^{55}$ y otro, en el monasterio de clarisas de Santa María de Jerusalén, este último, casi con toda seguridad, el códice objeto de nuestro estudio. A este primer corpus de traducciones al catalán de la segunda regla de santa Clara, Pere Bohigas añade un ejemplar que en su momento -en los años 1960- localizó en poder del librero Luís Fortuny, y que en el siglo XVIII pertenecía al convento de la Trinidad de Valencia, de monjas clarisas. Si tenemos en cuenta que en el año 1494 y en el momento en que el convento de Jerusalén de Barcelona pasó a la regla urbanista, llegaron a esta comunidad un grupo de monjas procedentes del convento de Valencia, esta versión poco conocida y hasta el momento en paradero desconocido, presenta también interesantes conexiones con Santa María de Jerusalén. Para Bohigas, que solo reproduce el folio que contiene una inicial historiada, sería un códice datable a finales del XV y con un estilo que se acercaría al arte de los iluminadores italianos. $^{56}$

No es nuestro objetivo y sin duda se escaparía de nuestro trabajo realizar un estudio pormenorizado de lo que serían cuatro versiones medievales (dos de ellas en la actualidad desaparecidas: la que describe Saldes en 1921 y la que señala Bohigas en los años 60) de la regla de santa Clara en catalán; ni tampoco realizar su «stemma codicum». Pero es interesante anotar las conexiones existentes entre ellos y los elementos que se repiten. Para empezar, el códice conocido como "versión 1» de Pedralbes y que toda la bibliografía clasifica como el más antiguo, ${ }^{57}$ no presenta ninguna miniatura y acoge aún la versión original en latín de la regla

\footnotetext{
53 Anzizu 1897.

54 Saldes 1912a, 1912b, 1912c

55 Ni Castellano, ni González Beltinski y Rubió Rodon 1982 hablan de este códice. En cambio, Sor Eulàlia Anzizu, al hablar de la regla que se seguía en Pedralbes, transcribía y comentaba la cronología de la orden de santa Clara donde se diferencian los monasterios que siguen la primera regla y los de la segunda regla, «segons se llegeix en lo darrer full d'un dels còdexs antics de la Santa Regla de Pedralbes» (Anzizu 1897, 8). En la actualidad el monasterio de Pedralbes conserva solo 3 manuscritos con la Regla: la versión 1, ya comentada; y dos manuscritos más de cronología claramente posterior: uno con letra del siglo XIX, texto en catalán y rúbricas de la Regla en rojo y en latín, y sin ningún tipo de decoración (iniciales, AHRMSMP R-24 bis). Otro también con letra moderna, siglo XVI rúbricas de la Regla en rojo y en latín, y sin ningún tipo de decoración (iniciales), tan solo en este caso una línea roja enmarcando el texto (AHRMSMP, R-25).

56 Bohigas 1960-1967, 50, núm 843, fig, 155.

57 Por ejemplo, datación en TRANSLAT: an nim. posterior a 1327.
} 
junto a la traducción catalana. ${ }^{58}$ Por el contrario, tanto en el caso que nos ocupa, esto es, el manuscrito procedente del convento de Jerusalén - hoy en la $\mathrm{BC}$-, como el que describe sucintamente Bohigas y que procedería de la Trinidad de Valencia, aparece en el primer folio una inicial miniada con una temática y composición similar, aunque con diferencias. Así, en el ejemplar catalogado por Bohigas, aparece el pontífice sentado y al fondo una imagen que podría tratarse de un cardenal, y frente a él santa Clara acompañada de una monja. El Papa y Clara cogen entre sus manos un libro (la Regla). En el caso que nos ocupa, los protagonistas de la escena son los mismos, aunque en número y disposición diferente: ahora son 2 los cardenales que claramente se sitúan junto al pontífice; y dos hermanas que acompañan a Clara que lleva ella misma el libro de la Regla. En ambos manuscritos, la miniatura ocupa una posición similar en el reverso del primer folio. Respecto al contenido, los dos manuscritos cuentan, a tenor del único folio publicado por Bohigas, con la bula de Urbano en catalán. ${ }^{59}$ Las analogías entre uno y otro códice son pues evidentes. Analogías que pueden extenderse también al manuscrito de Pedralbes, descrito en su momento por Saldes, ya que este cuenta también, como el de Jerusalén, con la carta del cardenal Orsini en catalán dirigida a las clarisas y el texto con la cronología de la orden de santa Clara. En los tres casos, además, se trata de códices que presentan únicamente el texto de la Regla en catalán, y solo las rúbricas de los capítulos se mantienen en latín. Finalmente, la Versión-1 de Pedralbes se divide en 28 capítulos, a diferencia de la de Jerusalén, objeto de nuestro estudio, que presenta 26 capítulos, ya que no aparecen explícitamente el capítulo «De les sors que van deffora» (que se incluye dentro del capítulo «Quod sorores in monasterio recluse continue morentur») ni el epígrafe «Del poder de l'abadessa», cuyo contenido se integra en el capítulo referente a la profesión de las monjas «De sororibus recipiendis et de earum professione $\Perp .^{60}$

Sin duda, aunque de nuevo caería fuera de nuestro objetivo, sería importante situar esta cadena de manuscritos con la Regla de Urbano IV en catalán, en un corpus más amplio de traducciones a las lenguas romances. Y en este sentido, valorar y significar el papel que pudieron tener las comunidades monásticas femeninas (como las de Santa Clara de Vilafranca, Santa Maria de Jerusalén, Santa Maria de Pedralbes o la Santísima Trinidad de Valencia) en este proceso de traducción a las lenguas vernáculas, que es también el de la consolidación de una lengua. ${ }^{61}$

58 Presenta sin embargo iniciales afiligranadas, rojas y negras, de fino trazo y composición.

59 En el archivo del monasterio de Sant Antoni i Santa Clara de Barcelona (de la orden clarisa hasta 1513 cuando pasaron a la familia benedictina) se conserva un pergamino con la copia de la bula «Beata Clara». AMSBM, MSCB, Col.lecció de pergamins, núm. 842.

60 La división en capítulos no existe en el documento original. De ordinario, según, Ignacio Omaechevarría $(2004,330)$ se divide en 26 capítulos.

61 En el caso de la regla benedictina traducida al catalán, por ejemplo, nuestros estudios en torno a la cultura libraria (literacy) y la cultura material y su inscripción espacial y performativa en el monasterio de Sant Antoni i Santa Clara de Barcelona, han confirmado la adscripción a esta comunidad de un manuscrito datado en 1519 conservado en la Biblioteca de la Abadía de Montserrat que contiene la regla de San Benito al catalán, justamente pocos años después de su paso de la familia clarisa a la benedictina. Véase Garí y Jornet-Benito 2017.

\subsection{Los textos que acompañan la Regla}

Los textos que acompañan la traducción de la regla en nuestro manuscrito son interesantes para contextualizar la promulgación y difusión de este texto normativo. Para la historia de la orden de Santa Clara, la regla segunda o de Urbano IV (1263) supondría la etapa final de un recorrido normativo que se habría iniciado con la Forma vitae del cardenal Hugolino (1219), recogiendo elementos de las Reglas precedentes e incorporando algunas novedades como que las monjas estarán confiadas no a la jurisdicción de los frailes menores, sino a la del cardenal protector. ${ }^{62}$ Vemos que es esta figura, el cardenal Juan Gaetano Orsini, futuro papa Nicolas III, quien, en su carta dirigida a las clarisas, copiada en el primer folio de nuestro manuscrito, en catalán, se preocupa de la traducción y la calidad y precisión de esta «transladar-la havem feta diligentment de mot a mot, no res mudat ne disminuït ne aiustat algunes rúbriques deiús scrites solament exceptades»; de su producción o escritura «Per ço que a semblança e forma de aquell façau la dita Regla scriure per a tots los vostres monestirs»; y de su conservación «en totes les províncies ab fil de / seda pendent bullada per manament nostre / en diversos lochs fos guardada». (Véase la trasnscripción completa de la carta en el Apéndice).

El papa Urbano IV, por su parte, en la bula Beata Clara ${ }^{63}$ que confirma la Regla, realizó una importante operación de clarificación de las distintas denominaciones de monjas que hasta entonces convivían en la familia clariana, de inspiración damianita «nosaltres e les altres ${ }^{64}$ qui prometeren aquell sien nomenades sots diversos noms, algunes vehades sors, altres vegades senyores, e moltes vegades monials, e algun temps pobres encloses de l'orde de Senct Damià» para agruparlas bajo un denominador común y se llamen de la orden santa Clara «E axí nós arbitrant ésser cosa còngrua e decent que lo vostre orde sia insignit e nomenat per lo nom de sancta Clara, e puys segons és dessús posat en ella ha pres los feels principis de la sua institució». En esta operación la figura central es Clara «la benaventurada Clara que per nom e per virtut clareia e resplendex per la gràcia divinal pervenguda e per exemples loables e salutífers" (Véase la transcripción de la bula entera en el Apéndice).

Nuestro manuscrito se cierra con una Cronología de la orden de Santa Clara que sitúa definitivamente la orden clariana en su origen y en sus principales episodios: una similar referencia a Francisco (Anno Domini MCCVI beatus Franciscus incipit ordine fratrum minorum) y a Clara (Anno Domini $M$ CC XII incipit ordine sancte Clare); y la incorporación de otro nombre, san Antonio de Padua, a la tríada de santos que

62 Véase otros elementos de contenido, definidores de esta normativa en Omaechevarría 2004, 330-342.

63 El monasterio de Sant Antoni i Santa Clara de Barcelona conserva una copia de esta bula, «Beata Clara», aunque no entera. AMSBM-MSCB, Col.lecció de pergamins, núm. 842. Transcripción en Jornet-Benito 2005, 57-58. Ignacio Omaechevarría presenta el texto latino de estos fragmentos de la bula siguiendo la edición del Bulario Franciscano y ofrece también su traducción al castellano (Omaechevarría 2004, 333335). No se conoce hasta el momento la traducción al catalán de esta bula, que ofrecemos completa en el Apéndice.

64 Confrontando la traducción castellana que ofrece Omaechevarría con esta versión catalana que presentamos, hay una significativa diferencia: donde se habla de "vosotras y otras que la profesan» en la primera se ha cambiado por la significativa y directa alusión a una a un «nosaltres e les altres». 
aparecerán desde entonces en la mayor parte de los calendarios de los libros litúrgicos (Anno Domini MCCXXXI obiit beatus Anthonius de Padua XIII die iunii). Para la orden concreta de Santa Clara, se marcará la diferenciación entre los conventos que viven bajo la regla Primera o de santa Clara (todos los de la provincia de Aragón. Excepto los 5 que se mencionan a continuación) y los que lo hacen baja la Segunda o de Urbano IV (Santa Maria de Pedralbes, Sant Antoni i Santa Clara Clara de Barcelona, ${ }^{65}$ Santa Clara de Castelló d’Empúries, Santa Clara de Vilafranca y santa Clara de Girona). Bajo esta regla el manuscrito incorpora también a todos los monasterios de las provincias de Alemania e Italia (Véase la transcripción entera de esta Cronología en el Apéndice).

\subsection{Las marcas de uso del manuscrito}

En las últimas décadas y desde distintas disciplinas se ha avanzado enormemente, en direcciones hasta hoy escasamente exploradas, en relación sea con la «materialidad» sea con la «espacialidad» de los objetos. ${ }^{66}$ En consecuencia existe en la actualidad un indudable interés por abordar el estudio de los objetos tanto en su fisicidad como a través de la red de significaciones que crean sus contextos de uso, espacio y relación performativa. ${ }^{67}$ En este marco se inscriben también las más recientes investigaciones sobre libros, lecturas y manuscritos. ${ }^{68}$ Estos estudios abordan, el objeto en sí mismo, mostrando cómo, en su materialidad, el manuscrito o el libro nos habla desde las huellas, textuales o no, que han ido dejando en él los procesos de producción, manipulación y uso.

Nuestro manuscrito conserva pocas marcas de uso que nos acerquen a las prácticas de lectura y recitación de su texto. Pocas, si las comparamos, por ejemplo, con las que se conservan en el manuscrito de Pedralbes, donde además de las palabras o breves frases que pueden aparecer en algunos de los márgenes (y que veremos también se da en nuestro manuscrito), hay un extenso repertorio de marcas (figuras de manos y dedos) que señalan frases o fragmentos de muchas de las páginas de la Regla.

En nuestro caso, todas las anotaciones al margen se refieren a la frase: "No lligen» (No lean), que parecería aludir a la no lectura o recitación, posiblemente en el contexto de una lectura comunitaria del texto de la Regla en el refectorio. Concretamente, se encuentra en:

- F. 21. No lligen, en el margen superior, antes de la rúbrica Qualibet sorores serviciales mittantur. De les servicials o sors que son tingudes axí com les altres ...

- F. 21 v. No lligen, en el margen izquierdo, junto a la rúbrica, Qualiter capellanus et conversorum vivere valeant Lo capellà si.s volrà obligar al monestir ...

- F. 25. No lligen, en el margen superior. En el folio con la rúbrica Qualibet nulla ex sororibus accedant ad curiam romanan. Per ço que ocasió e manera sia tolta als discursos perillosos e nocius, manam ...

65 En el manuscrito esta comunidad aparece con el nombre de "Sancti Danielis Barchinone», una denominación que aparece en algunos documentos por estar junto a la puerta homónima de la muralla de Barcelona.

66 Bynum 2011.

67 Lavan, Swift y Putzeys 2007.

68 Rudy 2015, 2016.
- F. 28 v. No lligen, en el margen inferior, bajo la rúbrica De cardinali huius religionis.

Imposible determinar si tales anotaciones fueron incorporadas por la comunidad de origen, Vilafranca, o ya en su nuevo emplazamiento, en Barcelona, fusionadas con las de Jerusalén. Las características paleográficas de esta letra no acercarían más propiamente a una letra de finales del siglo XVI-XVII, que podría también relacionarse con la marca de propiedad "Del convent de les monges Hierusalem de Barcelona» que aparece, como hemos comentado, en el reverso del primer folio.

\section{LA REGLA EN MANOS DE QUIENES LA POSEYERON}

En el interior de una comunidad, la Regla significa la tradición y la memoria de la orden o de la familia monástica; y por lo tanto, ocupará un lugar importante en la cultura escrita del cenobio. Es muy probable que las comunidades tuvieran más de un ejemplar, a veces uno en latín y otro en vulgar, uno de ellos para recitar, leer y consultar; el otro, destinado a algún ritual importante, como la liturgia de la bendición y la de imposición de los hábitos. Al ser además un texto de carácter normativo que marcaba aspectos diversos esenciales para la vida en común, ocupaba también un papel esencial en el camino de iniciación de las novicias. ${ }^{69}$

Es en esta última función que aparece explícitamente en uno de los capítulos de la Regla, De sororibus recipiendis et de earum professione, en la formación y aprendizaje de las novicias y con la mediación de la maestra: «E totes les dones ia rebudes dins lo monestir e clastra, tallats de costum los cabells posen tantost lo hàbit secular e sia'ls assignada una maestra, la qual les informe en les disciplines e costums de la Regla» (f. 6). Más tarde, pasado el año de noviciado, la Regla volverá a estar presente en la ceremonia de profesión: "faran professió en les mans de l'abadessa devant tot lo convent en aquesta forma: Yo sor (A) promet a Déu e a la benaventurada en tots temps Verge Maria, e al benaventurat sent Francesch e a la benaventurada sancta Clara e a tots los sancts, viure sots la regla per lo senyor Papa Urbà IV a l'orde nostre atorgada tot lo temps de la mia vida, en obediència, sens propri e en castedat e encara sots clausura segons per la matexa regla és ordenat» (ff. 6-6v.).

La importancia de esta promesa y el cumplimento de esta normativa vuelven a recordarse en el último capítulo de la Regla (Rubrica quod regula non negligatur a sororibus, f. 29 v.), donde se precisa además el lugar y el tiempo que su lectura ocupará en la cotidianidad y ritmo de la comunidad y de cada monja: "la dita regla vos sia legida una vegada per cascun spay de quinze en quinze dies». De esta manera - sigue el texto de la Regla - esta podrá convertirse en un "espejo» para cada una de las hermanas: "Mas per tant que axí com en l'espill vos purau en aquesta regla mirar, e que per oblivió (sic) o necligència (sic) no dexeu alguna cosa, la dita regla vos sia legida una vegada per cascun spay de quinze en quinze dies. E llà hon vos trobàreu fer les coses que són scrites feu ne gràcies a Déu donador de tots béns. Mas Ilà hon cascuna veurà que li fall alguna cosa, dolgàs del passat e guardes del esdevenidor pregnat que li sia dexat lo deute e

\footnotetext{
69 Fuster 2002, 8.
} 
que d'allí avant no cayga en temptació. Donchs a ningú dels hòmens sia lícit per qualsevol manera infringir o trenquar aquesta letra de nostra constitució, concessió, confirmació e absolu-/-ció ne per gosar temerari a ella contravenir. Mas si algú presumirà tentar açò, conexerà en córrer la indignació de Déu omnipotent e dels benaurats sent Pere e sent Pau apòstols seus» (ff.. 29 v.-30).

Significativa esta referencia directa al espejo, en cuanto, siguiendo a Delir Brunelli, se trata de un concepto clave y peculiar en la espiritualidad de Clara, presente en sus escritos. Concretamente, el pasaje en el que Clara habla de una "cadena de espejos» se encuentra en la primera parte del Testamento, donde desarrolla justamente el tema de la vocación. En esta cadena de espejos se sitúan además las hermanas clarisas, en donde: «el primer eslabón es Jesucristo, aunque no se mencione su nombre en el texto; el segundo eslabón lo forman Clara y las primeras Damianitas; el tercero, las futuras hermanas»; o, en otras palabras; "Jesucristo, espejo de la divinidad y espejo en su humanidad; Clara y las primeras damianitas, espejo de Cristo para las futuras hermanas; las primeras damianitas y las futuras hermanas, espejo de Cristo para quienes viven en el mundo». ${ }^{70}$

\section{CONCLUSIONES}

El análisis de un manuscrito, la Regla de Urbano IV, claramente presente y necesario en el espacio monástico y en la cultura escrita de las comunidades de clarisas, nos ha permitido en primer lugar situarlo junto a otros manuscritos conservados o en la actualidad en ubicación desconocida, y que enriquecen de manera importante el corpus de versiones en catalán de esta Regla hasta ahora conocidas.

La conexión de este manuscrito con diferentes comunidades de clarisas, desde la posible comunidad de origen (el monasterio de Santa Clara de Vilafranca del Penedès) hasta la comunidad que lo recibió con la fusión de ambos monasterios (Santa María de Jerusalén de Barcelona) ha posibilitado trazar dos momentos diferentes en la historia de la orden de santa Clara: una primera comunidad, nacida dentro de la segunda orden a principios del siglo XIV, que, en un esquema fundacional característico, recibe las primeras hermanas de un monasterio existente -el cual desarrolla en su territorio una labor fundacional en red-y así mismo cuenta con el significativo impulso, en su fundación y consolidación, de la monarquía catalana. Una segunda comunidad, en su origen nacida como una comunidad de terciarias, que poco después, en una dinámica bastante habitual, a finales del siglo XV, pasa a la orden segunda, acogiéndose a la regla urbanista.

Finalmente, tanto las dinámicas de reforma (recordemos que una de las versiones comentadas procedería de Santa María de Jerusalén donde llegaría desde la Trinidad de Valencia portada por las monjas que emprenderían su reforma) como la historia particular de una comunidad (la de Vilafranca del Penedès), permite abrir una interesante línea de investigación: cómo el libro puede funcionar de potente conector entre comunidades de lectoras, vinculando generaciones en este caso dentro de una misma familia monástica. ${ }^{71}$

\footnotetext{
70 Brunelli 2002, 223-224.

71 Shleif y Schier 2016.
}

\section{APÉNDICE}

\section{A) CARTA (ff.1-1v)}

Iohan per la misericòrdia divinal dia/cha cardenal de sent Nicholau en lo / carrer Tullia.

A les amades filles en Christ to-/-tes les abadesses e sors encloses de l'orde de / sancta Clara tramet salut en lo Senyor. Atte / nent que no.s poria fàcilment provehir que en to-/-tes les províncies e monestirs se hagués la / regla per lo sanctissím pare e senyor Urbà sobirà / bisbe los dies passats sots la sua butlla a vós / donada. Per ço doncs que la dita regla sots / butlla papal en totes les províncies ab fil de / seda pendent bullada per manament nostre / en diversos lochs fos guardada, transladar-/-la havem feta diligentment de mot a mot / no res mudat ne disminuït ne aiustat, al-/-gunes rúbriques deiús scrites solament excep-/-tades. Lo qual treslat matex ab deguda solici-/tut a l'original escoltat e plenàriament corre-/-git sots la munició e seguretat de nostre segell / vos havem determenat trametre. Per ço que / a semblança e forma de aquell façau la dita (f.1 v) Regla scriure per a tots los vostres monestirs. De la qual Regla tal és lo tenor. ${ }^{72}$

\section{B) BULA (ff.2-4)}

${ }^{73}$ Urbà bisbe servent / dels servents de Déu / a totes les ama-/-des filles en Christ / abadesses e sors / encloses del orde / de Sancta Clara tra-/-met salut e be-/-nedicció apostolical.

${ }^{74}$ La benaventurada Clara que per nom e per / virtut clareia e resplendex per la gràcia divinal / pervenguda e per exemples loables e salutífers / (f.2) del benaventurat confessor de Ihesu Christ sanct Frances-/ch informada, e per les sues doctrines instrui-/-da menyspreà fortment e esquivà les rique-/-ses e obres de aquest món e sàviament elegí / religiosament viure. E pus que hac pres / lo hàbit de la sagrada reliogió 75 per via estre-/-ta dels manaments del Senyor ab cor am-/-ple corregué. La qual via du a la eternal / vida aquells qui van per ella.

${ }^{76} \mathrm{E}$ Ihesu / Christ qui és appellat pedra ha volgut que / aquesta fos la primera pedra en lo edifici del / vostre orde mostrant en ella evidentment que / aquest tal edifici a ella era molt plasent, ha /l.a exalçada certament en títol de santedat per / ço que ella clareiàs e resplandís per honor /puys que ha resplendit e clareiat per mundícia/ de vida. E que la institució de la venerable / religió e los mèrits de la aprovada patro-/-na e quasi instituent de dit orde provassen e / demostrassen aquell ésser venerable e dig-/-ne de honor. Lo qual orde has pres en sa (f.2 v.) persona sant e loable principi.

${ }^{77} \mathrm{En}$ aquest vostre orde en temps passat s'a esdevengut que / nosaltres e les altres qui prometeren aquell si-/-en nomenades sots diversos noms: al-/-gunes vegades sors, altres vegades se-/-nyores, e moltes vegades monials, e /

\footnotetext{
72 Sigue rúbrica en rojo: «Aquesta és la Regla per lo sanctíssim pare papa Urbà quart dada e confermada a les sors de sancta Clara en I'any mil e docents LXIII, a XV dies de ans de les kalendes de noembre, en lo temps de frare Bonaventura ministre general de l'orde dels frares minors».

73 U, inicial iluminada.

74 Calderón.

75 Sic

76 Calderón

77 Calderón
} 
algun temps pobres encloses de l'orde de Senct / Damià. ${ }^{78} \mathrm{E}$ sots aquesta diversitat de noms vos són estades atorgades diverses gràcies e / letres, privilegis e indulgències de la cadi/-ra apostolical. Així, per Gregori papa de feel recor-/-dació predecessor nostre lavors bisbe de Òstia e / del vostre orde havent cura, com encara per / los altres. E açò per la diversitat de regla e forma de viure a les observances de les quals / algunes de vosaltres se són solemnament / obligades.

${ }^{79}$ Per la qual cosa, amades filles / en Christ a nos fon supplicat humilment que / curássem en signir e nomenar lo dit vostre / orde per títol de cert nom. E per tolre tot scrú/-pol de les vostres consciències absolvent vos mi-/(f.3)sericordiòsament de aquestes diversitats de obser-/-vàncies e dels vots de aquelles fets e pro-/-mesos, vos donássem certa forma de vi-/-ure. ${ }^{80} \mathrm{E}$ axí nós arbitrant ésser cosa còngrua / e decent que lo vostre orde sia insignit e no-/-menat per lo nom de sancta Clara, puys segons / és dessús posat en ella ha pres los feels prin-/-cipis de la sua institució. $E$ segons ferma-/-ment crehem per los seus mèrits e per sa in-/-tercessió és davant Déu guardat e defès / e davant los hòmens per laors exalçat /e ampliat per favors. De consell de nostres / frares determenam que lo vostre dit orde / de aquí avant sia appellat e nomenat / Orde de sancta Clara.

${ }^{81} \mathrm{E}$ statuim e ordenam / que totes les inmunitats e privilegis, in-/-dulgències e letres sots qualsevol nom / a vosaltres o al dit vostre orde atorgades / per la seu apostilical obtinguen aquella corrobo-/-ració de fermetat e virtut. E axí de aquelles / puxau usar com si del principi en ça sots (f. 3 v.) lo títol de aquest nom e sots aquesta nomi-/-nació vos fossen estades atorgades. ${ }^{82} \mathrm{E}$ per tant que bé e alegrament ensemps habi-/-teu e que sots la diversitat de les dites ob-/ servàncies no siau en la manera del viure vistes diferentes. $\mathrm{E}$ perquè ab hun cor e hun / voler aneu e habiteu en la casa de Déu. Vi-/-stes totes les regles dessús dites e spe-/-cialment e ab major diligència atenent / aquella lo qual dessús dit predecessor nostre / lavors bisbe Hostiench se mostrà haver / vós donada. Ab consell de nostres frares per / tenor de les presents letres a vosaltres e a / les successores vostres atorgam e confermam / la regla e forma de viure en les presents / notada e inserida. La qual en tots los mo/-nestirs del vostre orde fa tots temps obser-/-vada in perpetuum, ${ }^{83}$ e de la plenitud de la potestat apostolical de totes les altres regles / e formes e vots dessús posats absolven / totes aquelles que de vosaltres hauran (f. 4) promesa e votada aquesta regla o forma per nós a vós atorgada e confermada. La qual regla és aytal $(. . .)^{84}$

C) Cronología de LA ORDEN (ff. 31-31 v.)

${ }^{85} \mathrm{Anno}$ Domine MCCVI beatus Ffrancischus íncipit ordine fratrum minorum.

${ }^{86}$ Anno Domine MCCXII incipit ordine sancte Clare.

$\begin{array}{ll}78 & \text { Calderón } \\ 79 & \text { Calderón } \\ 80 & \text { Calderón } \\ 81 & \text { Calderón } \\ 82 & \text { Calderón } \\ 83 & \text { Sic } \\ 84 & \text { Empieza propiamente el texto de la Regla: «In nomine Domini. } \\ & \\ 85 & \text { Calderón. } \\ 86 & \text { Calderón. }\end{array}$

${ }^{87}$ Anno Domine MCCXXI incipit ordine fratrum et sororum de penitencia in propiis domibus existencium.

${ }^{88}$ Anno Domini MCCXXVI nonas octobris beatus Franciscus migravit ad Dominum.

${ }^{89}$ Anno Domini MCCXXXI obiit beatus Anthonius de Padua XIII die iunii.

${ }^{90}$ Anno Domini MCCLIII V idus augusti dominus Inocencius papa IIII confirmavit regula sancte Clare, et sui sigilli munimine roboravit pontificatus sui anno primo. Et post tres dies beata Clara clausit diem extremum.

${ }^{91} \mathrm{Et}$ sub ista regula vivint omnes sorores provincie Aragonum, exceptis quinque monasterii qui sunt in custodia Barchinone: S. Petre Albe, Sancti Danielis Barchinone, Castilionis, Villefranche et Gerunde, ut habetur in cronicis ordinis.

(f.. 31 v.) ${ }^{92}$ Anno Domini MCCLXIII XV kalendas novembris Urbanus pape IIII regulam sancte Clare ordinavit et viventes in ea sorores sancte Clare apellari mandavit. Et sub ista regula sunt fere omnia monasteria Alamanie et Ytalie provinciarum et $\mathrm{V}$ monasteria custodie ut dicti est.

${ }^{93} \mathrm{Et}$ eodem anno Bonaventura minister generalis ordinis minorum capitulum generale celebratum Parisi et protectore ordinis assistente ad supplicacionem eorundem ab obsequis earum fuerint absoluti et ex consequenti domino lohanni prefato protectori usque fuit ordo commissus.

${ }^{94}$ Demum Anno Domini MCCXC tempore domino Bonifaci pape VIII, Matheus cardinalis et protector dicti ordinis curam visitacionis et correctionis generali ministro et provincialibus duxit committetum illorum. monastiorum que ex sua regula vel ex privilegio subsunt cardinali eorum gubernatori secundum regulam Urbani pape.

\section{BIBLIOGRAFÍA CITADA}

Anzizu, Eulàlia. 1897. Fulles històriques de Santa Maria de Pedralbes. Barcelona: Estampa de F. Xavier Altés.

Azcona, Tarsicio. 1957. «Reforma de las clarisas de Cataluña en tiempo de los Reyes Católicos». Collectanea Franciscana 27: 5-51.

Boadas i Llavat, Agusti. 2014. Els Franciscans a Catalunya: història, convents i frarades (1214-2014). Lleida: Pagès Editors.

Bohigas, Pedro. 1960-1967. «Inventario de códices miniaturados o iluminados de procedencia catalana o existentes en las bibliotecas catalanas». En La llustración y la decoración del libro manuscrito en Cataluña, III, 145-223. Barcelona: Asociación de Bibliófilos.

Botinas, Elena, Julia Cabaleiro y Maria del Angels Durán. 2002. Les beguines. La Raó Il.luminada per Amor. Barcelona: Publicacions de l'Abadia de Montserrat.

Brunelli, Delir. 2002. Clara de Asís, Camino y espejo. Madrid: BAC.

Bynum, Caroline. 2011. Christian Materiality: An Essay on Religion in Late Medieval Europe. Brooklyn: Zone Books.

Castellano i Tresserra, Anna. 1998. Pedralbes a l'edat mitjana: història d'un monestir femení. Barcelona: Publicacions de l'Abadia de Montserrat.

Castellano i Tresserra, Anna. 2014. «El projecte fundacional del monestir de Santa Maria de Pedralbes i el palau de la reina Elisenda

\footnotetext{
87 Calderón.

88 Calderón.

89 Calderón.

90 Calderón.

91 Calderón.

92 Calderón.

93 Calderón

94 Calderón.
} 
de Montcada a través de dos inventaris del 1364». Anuario de Estudios Medievales 44 (1): 103-139. https://doi.org/10.3989/ aem.2014.44.1.04

Castro y Castro, Manuel de. 1989 «Monasterios hispánicos de clarisas desde el siglo XIII al XVI» Archivo íbero-americano 49 (193-194): 79-122.

Coll, Mari Carme, Xavier Cazeneuve y Josep Hernando. 1999. El manual de Joan de Cabreny (1385-1386). Barcelona: Fundació Noguera.

Costa Badia, Xavier, Marta Sancho i Planas y María Soler Sala. 2017. «Monacato femenino y paisaje. Los monasterios de clarisas dentro del espacio urbano en la Catalunya medieval». En Clarisas y dominicas. Modelos de implantación, filiación, promoción y devoción en la Península Ibérica, Cerdeña, Nápoles y Sicilia, ed. Gemma Colesanti, Blanca Garí y Núria Jornet-Benito, 449-486. Firenze: Firenze University Press.

Coy Cotonat, Agustín. 1909. Vilafranca del Penadés. Su historia y monumentos. Barcelona: Imprenta Francisco J. Altés y Alabart.

Español, Francesca. 2008. «Els convents de Sant Francesc i santa Clara de Vilafrana. L'arquitectura i els seus promotors». En De la Marca hispànica a les terres de Marca: el Penedès, 249-270. Vilafranca del Peneds: Institut d'Estudis Penedesencs.

Español, Francesca. 2009. «Un preludio del Renacimiento: el libro iluminado durante el período tardogótico en Cataluña». En Arte de épocas inciertas. De la Edad Media a la Edad Contempornea, 285339. Madrid: Institución Fernando el Católico.

Fuster, Joan. 2002. Les Constitucions del convent de Sant Josep de València (segle XVI). València: Publicacions de la Universitat de València

García Oro, José. 1969. La reforma de los religiosos españoles en tiempos de los Reyes Católicos. Valladolid: Instituto «Isabel la Católica» de Historia Eclesiástica.

García Oro, José. 1971. Cisneros y la reforma del clero español. Madrid: Instituto Jerónimo Zurita.

Garí, Blanca. 2017 «What did Catalans Nuns Read? Women's Literacy in the Female Monasteries of Catalonia, Majorca and Valencia». En Nuns' Literacies in Medieval Europe: The Antwerp Dialogue, ed. Veronica O'Mara, Virginia Blanton y Patricia Stoop, 125-148. Turnhout: Brepols Publishers.

Garí, Blanca y Núria Jornet-Benito. 2017. «El objeto en su contexto. Libros y prácticas devocionales en el monasterio de Sant Antoni i Santa Clara de Barcelona». En Clarisas y dominicas. Modelos de implantación, filiación, promoción y devoción en la Península Ibérica, Cerdeña, Nápoles y Sicilia, ed. Gemma Colesanti, Blanca Garí y Núria Jornet-Benito, 487-511. Firenze: Firenze University Press.

Garí, Blanca, María Soler, Marta Sancho, Delfi Nieto-Isabel y Araceli Rosillo-Luque. 2014. «CLAUSTRA. Propuesta metodológica para el estudio territorial del monacato femenino». Anuario de Estudios Medievales 44 (1): 21-50. https://doi.org/10.3989/ aem.2014.44.1.01

González Beltinski, Margarida y Anna Rubió Rodon. 1982. «La Regla de l'Orde de Santa Clara de 1263. Un cas concret de la seva aplicació: el monestir de Pedralbes». Acta historica et archeologica mediaevalia 3: 9-46.

Graña Cid, María del Mar. 2017. «Clara de Asís y la implantación de los franciscanos en Castilla (c. 1220-1253). Autoría femenina en red». En Clarisas y dominicas. Modelos de implantación, filiación, promoción y devoción en la Península Ibérica, Cerdeña, Nápoles y Sicilia, ed. Gemma Colesanti, Blanca Garí y Núria Jornet-Benito, 223-246. Firenze: Firenze University Press

Jornet-Benito, Núria. 2005. Sant Antoni i Santa Clara de Barcelona: origen d'un monestir i configuració d'un arxiu monàstic (12361327). Tesi doctoral. Universitat de Barcelona. http://www.tdx. cat/handle/10803/119825

Jornet-Benito, Núria 2007. El monestir de Sant Antoni de Barcelona: l'origen i l'assentament del primer monestir de clarisses a Catalunya. Barcelona: Publicacions de l'Abadia de Montserrat.

Jornet-Benito, Núria. 2015. «Female Mendicant Spirituality in Catalan Territory: The Birth of the First Communities of Poor Clares». En Women in The Medieval Monastic World, ed. Karen Stöber y Janet Burton, 185-210. Turnhout: Brepols.
Lavan, Luke, Elle Swift y Toon Putzeys. 2007. Objects in context, Objects in use. Material Spatiality in Late Antiquity. Leiden - Boston: Brill.

Lehmijoki-Gardner, Maiju. 2004. «Writing eligious Rules as an Interactive Process: Dominican Penitent Women and the Making of Their Regula». Speculum 79 (3): 660-687.

Nieto-Isabel, Delfi. 2017. «Overlapping Networks. Beguins, Franciscans, and Poor Clares at the crossroads of a shared spirituality». En Clarisas y dominicas. Modelos de implantación, filiación, promoción y devoción en la Península Ibérica, Cerdeña, Nápoles y Sicilia, ed. Gemma Colesanti, Blanca Garí y Núria Jornet-Benito, 129-448. Firenze: Firenze University Press.

Omaechevarría, Ignacio. 1972. Las clarisas a través de los siglos. Madrid: Editorial Cisneros.

Omaechevarría, Ignacio. 2004. Escritos de Santa Clara y documentos complementarios. Madrid: BAC.

Paulí Meléndez, Antonio. 1941. Resumen histórico del Monasterio de Nuestra Señora de los Ángeles y pie de la Cruz de Barcelona. Barcelona: Talleres Gráficos Rex.

Paulí Meléndez, Antonio. 1970. El Reial Monestir de Santa Maria de Jerusalem de Barcelona (1454-1970). Barcelona: Tipografia Emporium.

Perarnau, Josep. 2009. «Beguins de Vilafranca del Penedès davant el tribunal d'Inquisició (1345-1346): de captaires a banquers?». Arxiu de Textos Catalans Antics 28: 7-210.

Rosillo-Luque, Araceli. 2013. "Habeat ecclesiam Santorum Blasy et Lazari edifficatam iuxta dictum eorum monasterium Sancte Clare: evidencias e hipótesis sobre la fundación de Santa Clara de Manresa». En Women's Networks of Spiritual Promotion in the Peninsular Kingdoms (13th-16th Centuries), ed. Blanca Garí, 167183. Roma: Viella.

Rosillo-Luque, Araceli. El monasterio de Santa Clara de Manresa (siglos XIV-XVII). Las clarisas en la Cataluña Central. Tesis doctoral. Universitat de Barcelona. https://www.tdx.cat/ handle/10803/461178

Rudy, Kathryn. 2011. Virtual Pilgrimages in the Convent Imagining Jerusalem in the Late Middle Ages. Turnhout: Brepols.

Rudy, Kathryn. 2015. Postcards on Parchment: The Social Lives of Medieval Books. New Haven: Yale University Pres.

Rudy, Kathryn. 2016. Piety in Pieces: How Medieval Readers Customized their Manuscripts. Cambridge: Open Book Publishers.

Saldes, Ambròs. 1912a. "Una versión catalana de la Regla de las clarisas. Siglo XIV». Estudios franciscanos VIII: 215-223.

Saldes, Ambròs. 1912b. «Una versión catalana de la Regla de las clarisas. Siglo XIV». Estudios franciscanos IX: 372-379.

Saldes, Ambròs. 1912c. "Una versión catalana de la Regla de las clarisas. Siglo XIV». Estudios franciscanos X: 49-57.

Sales, Agustín y Pedro Pascual Moles. 1761. Historia del Real Monasterio de la SSma. Trinidad: religiosas de Santa Clara... fuera de los muros de la ciudad de Valencia... Valencia: en la Imprenta de Agustin Laborda i Campo. Disponible en: https://bivaldi.gva.es/es/ consulta/registro.cmd?id=1440 [Consulta: 26/06/2017].

Sanahuja, Pedro. 1959 Historia de la seráfica provincia de Cataluña. Barcelona: Seráfica, DL.

Sanjust Latorre, Cristina. 2010. "L'obra del Reial Monestir de Santa Maria de Pedralbes des de la seva fundació fins al segle XVI: un monestir reial per a l'orde de les clarisses a Catalunya». Tesis doctoral. Universitat Autònoma de Barcelona. http://www.tdx.cat/ handle/10803/5200

Schleif, Corine y Volker Schier. 2016. Manuscripts Changing Hands. Wiesbaden: Harrassowitx Verlag.

Trenchs, Manuel. 1926. «Del monestir de Santa Clara de Vilafranca». Quaderns mensuals d'acció I: 238-240.

Torres Cortina, Miquel. 2004. «L'escriptura i el llibre a la Catalunya Central als segles XIII i XIV». 3 vols. Tesis doctoral. Universitat Autònoma de Barcelona. http://www.tesisenred.net/handle/10803/5539

Webster Jill R. 2000. Els franciscans catalans a l'edat mitjana. Els primers menorets i menoretes a la Corona d'Aragó. Lleida: Pagès. 